\title{
Methylation-specific electrochemical biosensing strategy for highly sensitive and quantitative analysis of promoter methylation of
}

\section{tumor-suppressor gene in real sample}

\author{
Shenglin Liu ${ }^{\mathrm{a}}$, Xuejun Zhang ${ }^{\mathrm{b}}$, Kebin Zhao ${ }^{\mathrm{c}, *}$ \\ ${ }^{a}$ Department of Laboratory Medicine, Xiqing Hospital of Tianjin, Tianjin 300380, China. \\ ${ }^{\mathrm{b}}$ Department of Immunology, Tianjin Medical University, Tianjin 300070, China \\ ${ }^{\mathrm{c}}$ Department of Laboratory Medicine, The First Hospital of Shanxi Medical University, Taiyuan 030001, China
}

\begin{abstract}
A handy and practical methylation-specific electrochemical biosensing strategy was developed by integrating bisulfite conversion and PCR amplification with high efficient electrochemical biosensor. The dual signal amplification of PCR and enzyme-catalyzed electrochemical sensing resulted in higher sensitivity of the proposed method. The primers for PCR and capture probes for amplicons binding were specifically designed to distinguish different $\mathrm{CpG}$ islands in the promoter regions of target gene, which further enhanced the specificity. The designed method showed very high sensitivity and specificity for DNA methylation analysis and was able to respond to about 8 copies of methylated promotor of secreted frizzled-related protein 2 (SFRP2) gene in 10,000 times of unmethylated genomic DNA. Moreover, the established biosensor was successfully verified for quantitative detection of SFRP2 promotor methylation in breast primary tumor tissues and subtle evaluation of SFRP2 promotor methylation status changes in real sample with the demethylating agent treatment. This proposed strategy presented a simple and pragmatic platform toward high sensitive and quantitative detection promoter methylation of tumor-suppressor gene for early diagnosis and prognostic assessment of cancer, as well as monitoring response to therapeutic agents.
\end{abstract}

Keywords: Electrochemical biosensor; DNA methylation; Tumor suppressor gene; High sensitivity; Practicability

* Corresponding author. Tel: 0351-4639519; Fax: 0351-4639519.

E-mail address: $\underline{\text { sxzhaokebin@163.com. }}$ 


\section{Introduction}

DNA methylation is the best-known epigenetic marker, which refers to that cytosine is modified with a methyl group at the 5'-position by the catalysis of a group of DNA methyltransferase enzymes after DNA replication. DNA methylation plays a critical role in many biological events, such as control of tissue-specific genes and germ-line genes, genomic imprinting, X-chromosome inactivation and prevention of chromosomal instability [1-3]. Aberrant DNA methylation is frequently observed in tumor cells with global hypomethylation and hypermethylation of the $\mathrm{CpG}$ islands in the promoter regions of tumor-suppressor genes [4, 5]. Furthermore, hypermethylation of the $\mathrm{CpG}$ islands is an early event in the development of cancer [6]. Thus, quantitative analysis of DNA methylation of the $\mathrm{CpG}$ islands in the promoter regions of tumor-suppressor genes can be serve as potential tumor biomarker for early diagnosis of cancer, monitoring tumor behavior, as well as measuring response of tumors to targeted therapy [7-9].

So far, many techniques have been applied to profile the methylation status of target genes. Generally, these DNA methylation analysis techniques mainly rely on either methylation-sensitive restriction enzyme (MSRE) digestion or sodium bisulfite conversion to distinguish methylated cytosine from unmethylated cytosine $[10,11]$. MSRE-based methods use MSRE to cleave DNA at specific unmethylated cytosine residues and leave the methylated DNA intact, are fast and simple $[12,13]$. But the dependence upon methylation-sensitive restriction sites limits their wide applications due to methylation of $\mathrm{CpG}$ dinucleotides may vary within one $\mathrm{CpG}$ island [13, 14]. Alternatively, the most widely applied methods for analysis of DNA methylation rely on sodium bisulfite to treat genomic DNA for converting cytosines, but not 5-methylcytosines, to uracil. In traditional methylation-specific PCR (MSP), the sodium bisulfite converted genomic DNA can be amplified with specific primers and the products are identified using gel electrophoresis [11]. 
However, this standard MSP approach offers only qualitative analysis result and has relative low sensitivity [15]. Real-time methylation-specific PCR provides a quantitative, high-throughput and real-time resolution [16, 17], but double-labeled probes and quantitative PCR apparatus make it too expensive and difficult to popularize [18]. Thus, the simple, inexpensive method for high sensitive and quantitative detection of DNA methylation is still an urgent demand.

In recent years, extensive efforts have been devoted to develop new biosensing strategies for high sensitive and specific analysis of DNA methylation, including fluorescence [19, 20], surface plasmon resonance [21, 22], electrochemistry [23], electrogenerated chemiluminescence [24] and colorimetry [25], et al. These biosensing strategies are mostly based on MSRE, which really provide useful tools for analyzing demethylase activity and screening demethylase inhibited drug. However, the inherent defect of restriction sites limits their application for comprehensive profiling methylation status of the $\mathrm{CpG}$ islands of target genes. In addition, the methyl-CpG binding domain (MBD) protein and anti 5-methylcytidine antibody were employed as recognition elements to build various biosensor for rapid analysis cytidine methylation $[20,22,26]$. But these biosensors lack the nucleic acid amplification like PCR or isothermal DNA amplification, constrainting the sensitivity and practicability of these biosensors for the analysis of real specimens containing low amounts of methylated DNA. Moreover, some nanomaterials-based biosensors have been designed to analysis the MSP product for improving the quantitative capability and analytical sensitivity of MSP [18, 27]. However, the variability of the nanomaterials and their bio-functionalization often affects the reproducibility and quantification, especially for the real samples [28].

Herein, aiming at further improving the simplicity, practicality and sensitivity of biosensor-based DNA methylation detection, a handy methylation-specific electrochemical 
biosensing strategy was developed by integrating bisulfite conversion and PCR amplification with high efficient electrochemical biosensor (Scheme 1). The dual signal amplification of PCR and enzyme-catalyzed electrochemical sensing resulted in higher sensitivity of the proposed method. The primers for PCR and capture probes for amplicons binding were specifically designed to distinguish different $\mathrm{CpG}$ islands in the promoter regions of target gene, which further enhanced the specificity. Secreted frizzled-related protein 2 (SFRP2) gene, an important tumor suppressor gene, can down-regulate Wnt signalling and antagonize tumorigenesis. The promoter hypermethylation of SFRP2 gene leads to abrogation of SFRP2 expression, activation of Wnt signalling, resulting in tumorigenesis [29]. Promoter hypermethylation of the SFRP2 gene is proved a high-frequent alteration in human cancers, and is qualified as a potential candidate biomarker for early detection and invasive prediction of cancer [29-31]. Therefore, this work used SFRP2 gene as a model to verify the practicability of the designed strategy. The proposed methylation-specific electrochemical biosensing protocol showed very high sensitivity and selectivity and was successfully applied to detection methylation status of SFRP2 promoter in breast primary tumor tissues and demethylation drug treated breast cancer cell lines. Thus, the designed electrochemical biosensing strategy presented a simple, pragmatic and inexpensive platform toward high sensitive and quantitative detection of promoter methylation of tumor-suppressor gene for early diagnosis of cancer.

$$
\text { Preferred position for Figure } 1 .
$$

\section{Experimental}

\subsection{Reagents}

6-mercapto-1-hexanol (MCH), Streptavidin-alkaline phosphatase (ST-AP), $\alpha$-naphthyl phosphate ( $\alpha$-NP), bovine serum albumin (BSA), salmon sperm DNA and 5-aza-2'-deoxycytidine (Aza) were 
purchased from Sigma-Aldrich (USA). Trichostatin A (TSA) were purchased from Cayman Chemical Co. (USA). AmpliTaq DNA Polymerase was purchased from ABI (USA). The oligonucleotides with the sequences shown in Table 1 were obtained from Shanghai Sangon Biological Engineering Technology \& Services Co., Ltd. (China). All other reagents were of analytical grade. All aqueous solutions were prepared using ultra-pure water $(\geq 18 \mathrm{M} \Omega$, Milli-Q, Millipore).

Preferred position for Table 1.

\subsection{Apparatus}

All electrochemical measurements were performed on a CHI660D electrochemical analyzer (CHI Co., TX) with a conventional three-electrode system composed of platinum wire as auxiliary, $\mathrm{Ag} / \mathrm{AgCl}$ electrode as reference, and a gold electrode (GE) as working electrode. The PCR was carried out using a S1000 Thermal Cycler (Bio-Rad Laboratories, USA). Gel images were captured on a Gel Doc XR+ Imaging System (Bio-Rad Laboratories, USA).

\subsection{Preparation of electrochemical biosensor}

A GE was polished with $0.05 \mu \mathrm{m}$ alumina slurries and ultrasonically treated in deionized water. The electrode was then soaked in piranha solution $\left(\mathrm{H}_{2} \mathrm{SO}_{4}: \mathrm{H}_{2} \mathrm{O}_{2}=3: 1\right)$ for 10 min to eliminate other substances followed by rinsing thoroughly with deionized water. $10 \mu \mathrm{L}$ of $1 \mu \mathrm{M}$ thiolated capture probe was dropped on the pretreated electrode surface and incubated overnight at $4{ }^{\circ} \mathrm{C}$. The resulting electrode was immersed into $100 \mu \mathrm{L}$ of $1 \mathrm{mM} \mathrm{MCH}$ solution for $1 \mathrm{~h}$ to occupy the left bare sites on electrode surface and obtain well-aligned DNA monolayer. The biosensor was rinsed with ethanol and deionized water. The prepared biosensor was further soaked in $0.1 \mathrm{M} \mathrm{pH}$ 7.4 Tris- $\mathrm{HCl}$ buffer containing $125 \mu \mathrm{g} \mathrm{mL}{ }^{-1}$ salmon sperm DNA and 2\% BSA for $30 \mathrm{~min}$, and rinsed 
with $0.1 \mathrm{M} \mathrm{pH} 7.4$ Tris-HCl buffer containing $0.05 \%$ Tween 20 . The incubation of salmon sperm DNA and BSA could effectively decrease the background response by blocking the nonspecific binding sites of oligonucleotides proteins, respectively.

\subsection{Preparation of Genomic DNA samples}

MDA-MB-231 and MCF-7 breast tumor cell lines were used in this study. The demethylation treatment of the two cell lines by Aza and TSA was carried out as described [32]. Typically, cells

were treated with $10 \mu \mathrm{M}$ Aza for 3 days and subsequently with $100 \mathrm{ng} \mathrm{mL}^{-1} \mathrm{TSA}$ for 24 hours. Fresh medium containing $10 \mu \mathrm{M}$ Aza was replaced every $24 \mathrm{~h}$. After treatment, cells were pelleted and washed with phosphate-buffered saline (PBS). Genomic DNA was extracted from the cell line pellets, primary breast tumors and normal breast tissue using QIAamp DNA Mini Genomic DNA Extraction Kit (QIAGEN) according to the instructions.

\subsection{Bisulfite conversion and PCR amplification}

Bisulfite conversion of DNA was carried out using EZ DNA Methylation-Gold Kit (ZYMO RESEARCH CORP.) according to the instructions. Typically, $130 \mu \mathrm{L}$ CT Conversion Reagent was added to $20 \mu \mathrm{L}$ of DNA sample in a PCR tube. The mix was placed in a thermal cycler to perform the steps of $98{ }^{\circ} \mathrm{C}$ for $10 \mathrm{~min}$ and $64{ }^{\circ} \mathrm{C}$ for $2.5 \mathrm{~h}$, and then was stored at $4{ }^{\circ} \mathrm{C}$ up to $20 \mathrm{~h}$ for complete bisulfite conversion. The reacted DNA was collected with supporting Zymo-Spin IC colunm. The bisulfite-converted DNA was amplified with the methylation-specific primer set or the unmethylation specific primer set for SFRP 2 (Table 1). The reaction mixture in a final volume of $25 \mu \mathrm{L}$ contained $1 \mu \mathrm{L}$ of bisulfite-converted genomic DNA, $1.5 \mu \mathrm{L}$ of $10 \mu \mathrm{M}$ each primer, $1 \mathrm{U}$ of AmpliTaq Gold DNA polymerase, $2.5 \mu \mathrm{L}$ of $10 \times$ Taq buffer, $2 \mu \mathrm{L}$ of $2.5 \mathrm{mM}$ of each dNTP and 2.5 $\mu \mathrm{L}$ of $25 \mathrm{mM} \mathrm{MgCl} 2$. After denaturing at $95{ }^{\circ} \mathrm{C}$ for $10 \mathrm{~min}$, the reaction for methylation-specific primer was carried out for 40 cycles of $94{ }^{\circ} \mathrm{C}$ for $30 \mathrm{~s}, 60{ }^{\circ} \mathrm{C}$ for $30 \mathrm{~s}$ and $72{ }^{\circ} \mathrm{C}$ for $30 \mathrm{~s}$. A final extension of $72{ }^{\circ} \mathrm{C}$ for $5 \mathrm{~min}$ was employed. For unmethylation-specific primer, the annealing 
temperature was changed to $58{ }^{\circ} \mathrm{C}$. PCR products were determined by running $10 \mu \mathrm{L}$ of PCR mixture in $2 \%$ agarose gel and observed under ultraviolet light.

\section{6 biosensing protocol}

PCR product was denatured by heating for $5 \mathrm{~min}$ at $100{ }^{\circ} \mathrm{C}$ in a water bath, and immediately chilled in ice to obtain denatured ssDNA. $10 \mu \mathrm{L}$ of denatured PCR product was dropped on the prepared electrochemical biosensor and incubated for $30 \mathrm{~min}$ at $37{ }^{\circ} \mathrm{C}$ for hybridization with the capture probe. $37{ }^{\circ} \mathrm{C}$ of hybridization temperature could effectively discriminate methylated and unmethylated PCR products according to the calculated melting temperatures and our pre-experiment. After washing with PBS contained $0.05 \%$ Tween 20, the biosensor was reacted with $10 \mu \mathrm{L}$ of $1.25 \mathrm{mg} \mathrm{mL}^{-1} \mathrm{ST}-\mathrm{AP}$ in $\mathrm{pH} 9.6$ diethanolamine buffer at $37^{\circ} \mathrm{C}$ for $30 \mathrm{~min}$. Then the biosensor was washed thoroughly with diethanolamine buffer containing $0.05 \%$ Tween 20 . Electrochemical measurement was performed in $\mathrm{pH} 9.6$ diethanolamine buffer containing $1 \mathrm{mg}$ $\mathrm{mL}^{-1}$ of $\alpha$-NP. The differential pulse voltammetry (DPV) measurements were performed from 0 to $0.6 \mathrm{~V}$ with pulse amplitude of $50 \mathrm{mV}$ and width of $50 \mathrm{~ms}$.

\section{Results and Discussion}

\subsection{Characterization of biosensor fabrication}

Electrochemical characteristics of biosensor fabrication were obtained by electrochemical impedance spectroscopy (EIS). $\left[\mathrm{Fe}(\mathrm{CN})_{6}\right]^{3-} /\left[\mathrm{Fe}(\mathrm{CN})_{6}\right]^{4-}$ was utilized as the redox probe and the semi circle diameter was equal to electron-transfer resistance (Ret) (Fig. 1). The bare GE exhibits an almost straight line that is characteristic of a reflecting excellent electrochemical conductivity (curve a). When the capture probe was self-assembled onto the bare electrode via Au-S bond, the Ret increased due to the poor conductivity of the DNA (curve b). $\mathrm{MCH}$ was then used to reduce the 
nonspecific adsorption on the biosensor surface through hydrophobic and electrostatic interaction, which resulted in the further increase of Ret (curve c). The binding of the PCR products amplified with biotinylated primer led to the Ret significantly increased (curve d). Afterwards, upon the streptavidin binding onto the electrochemical sensor surface, the Ret further increased (curve e). The results of EIS provided the direct evidences of successful stepwise fabrication of biosensor and subsequent binding and biosensing.

Preferred position for Figure 2.

\subsection{Feasibility of the designed method}

In the designed method, the bisulfite-converted genomic DNA was amplified through PCR with methylated primers and unmethylated primers containing biotinylated forward primer, respectively. Next, the biotin labeled PCR products was hybridized with methylation or unmethylated-specific capture probe, and bound with ST-AP for enzyme-catalyzed electrochemical detection of the level of DNA methylation. To examine the feasibility of the designed method, control experiments were conducted using MB231 breast cancer cell genomic DNA as the control for CpG methylation of SFRP2 gene and normal breast tissue genomic DNA as unmethylation control, respectively. MB231 breast cancer cell line has been observed to be full CpG methylation of SFRP2 gene promotor [29]. The DPV curve of methylation-specific electrochemical biosensor responding to MB231 breast cancer cell genomic DNA showed a well-defined oxidation peak which corresponded to the oxidation of a-naphthyl, the AP-catalyzed product of a-NP. Meanwhile, unmethylation-specific electrochemical biosensor showed little DPV signal for MB231 du to a very weak background response. Normal breast tissue, by contrast, only resulted in significant DPV signal with 
unmethylation-specific electrochemical biosensor. These results were in a good agreement with those obtained from gel image of conventional MSP and previous report [29]. Thus, the designed electrochemical biosensing strategy was proved to a useful method for analysis methylation status of target gene.

\section{Preferred position for Figure 3.}

\subsection{Optimization of biotin labeling}

To harmoniously combine enzyme-amplified electrochemical biosensor with PCR amplification, biotin labeling was tried to incorporate with PCR amplification and subsequently bind with ST-AP for enzyme-catalyzed electrochemical readout. We had intended to use biotin-11-dUTP to incorporate into the extended DNA chains during PCR amplification for biotin multiple labeling [33]. As shown in Fig. 2A, biotin-11-dUTP was incorporated into the PCR amplicon indeed and resulted in well-defined DPV signal. Interestingly, the obtained peak current increased with the decreasing rate of biotin-11-dUTP:dTTP, but was obviously lower than that of obtained with biotinylated forward primer. It was possibly due to that the bisulfite-converted genomic DNA contained very high ratio of Adenine-uracil pairing and its PCR amplification may be severely interfered by the incorporation of biotin-11-dUTP. In addition, biotinylated detection probe was also employed to hybridize with PCR product on the electrochemical biosensor surface. Unfortunately; the obtained DPV signal was more lower, which maybe owe to that the high abundance of primers in unpurified PCR product antagonized the hybridization with biotinylated detection probe. So, the optimal mean for biotin labeling was to use biotinylated forward primer. 


\subsection{Analytical performance of the designed method}

The sensitivity and quantification is critical to an analysis method for the evalution of methylation status of target gene. Because methylation frequently presents in a little subset of cells in a clinical specimen[15]. Under the optimal conditions, the DPV was employed to investigate the sensitivity of the fabricated biosensor by mixing different ratio of complete methylated SFRP2 gene promotor (MB231 breast cancer cell genomic DNA) into complete unmethylated SFRP2 gene promotor (normal breast tissue genomic DNA) with $250 \mathrm{ng}$ of total genomic DNA. As shown in Fig.5B, the DPV responses of methylation-specific electrochemical biosensor linearly decreased with the ratio of methylated SFRP2 gene promotor in a range from $100 \%$ to $0.01 \%$ methylated/unmethylated SFRP2 alleles. The linear curve of the DPV signals (Y) vs the logarithm of the methylated ratio of SFRP2 (X) was fitted to a regression equation of $\mathrm{Y}=5.346+1.288 \lg (\mathrm{X})$ $\left(\mathrm{R}^{2}=0.986\right)$ in the range of $0.01 \%-100 \%$. The limit of detection (LOD) for methylated SFRP2 gene promotor was defined to be $0.01 \%$ methylated/unmethylated SFRP2 alleles whose response was distinctly higher than that of $100 \%$ unmethylated SFRP2 gene promotor and according with the $3 \sigma$ rule. The LOD was equivalent to as little as $25 \mathrm{pg}$ of methylated DNA in an excess of $250 \mathrm{ng}$ of unmethylated DNA. In other words, the proposed biosensor was able to respond to about 8 copies of methylated SFRP2 gene promotor in 10,000 times of unmethylated DNA, as One cell genomic DNA is about $3 \mathrm{pg}$ [27]. The LOD of the proposed biosensing strategy was lower than that of conventional MSP using gel image (Fig.5A). It also remarkably lower than those of MSRE based biosensing strategies [19, 21, 23-25] and those of biosensors using (MBD) protein and anti 5-methylcytidine antibody as recognition elements [20, 22, 26], and was comparable with those of quantitative methylation specific PCR [16] and methylation-specific quantum dot fluorescence 
resonance energy transfer [27]. The ultrahigh sensitivity was attributed to the high efficiency of bisulfite conversion, the dual signal amplification of PCR and enzyme-catalyzed electrochemical sensing, and enhanced specificity of methylation specific primers and capture probe.

\section{Preferred position for Fig. 5}

\subsection{Quantification and monitoring of methylation status in real sample}

In order to evaluate the practical applicability for real sample analysis, the established biosensor was employed to detect SFRP2 promotor methylation in breast primary tumor tissues and estimate SFRP2 promotor demethylation in breast cancer cell lines as a function of response to DNA demethylating agent. As shown in Fig. 6B, the DPV signals of methylation-specific electrochemical biosensor responding to three breast primary tumor tissues were obviously different, indicating variant methylation levels of SFRP2 promotor and heterogenicity of tumor tissues, which could be confirmed with conventional MSP (Fig. 6A). The ratio of methylated SFRP2 promotor of three breast primary tumor tissues could be calculated to be about $0.2 \%, 0.7 \%, 65 \%$, respectively, according to the standard curve in Fig 5. The change of methylation status in MB231 and MCF-7 breast cancer cells was further quantitatively monitored with the established biosensor. As shown in Fig. 6B, the SFRP2 promotor methylation level of MB231 cells decreased from $100 \%$ to about 4.6\% and MCF-7 decreased from about $10.8 \%$ to $0.2 \%$ after the cells treated with Aza for 3 days and TSA for 24 hours, indicating the substantial demethylation effect. Compared with traditional PCR, the established biosensor held not only higher sensitivity but also excellent quantification ability for pragmatic application. These results demonstrated that the proposed methylation specific electrochemical biosensing strategy held competent sensitivity and specificity for quantitative 
analysis methylation level of tumor-suppressor gene and Subtle monitoring of methylation status changes in real sample.

Preferred position for Fig. 6

\section{Conclusions}

This work has demonstrated a high sensitive and specific electrochemical biosensing protocol for convenient and quantitative detection of promoter methylation of tumor-suppressor gene by harmoniously combining bisulfite conversion and PCR amplification with electrochemical biosensor. The designed method showed very high sensitivity and specificity for DNA methylation analysis of target gene and was able to quantitatively detect of methylation level of target gene promotor and subtly monitor methylation status changes in real sample. Moreover the proposed method don't need of complicated materials preparation and probe labeling and sophisticated instrument for signal readout. This proposed strategy would become a potential tool toward high sensitive and quantitative detection of DNA methylation biomarker for early diagnosis and prognostic assessment of cancer, as well as monitoring response to therapeutic agents.

\section{Acknowledgements}

This work was supported by National Science Foundation of China $(31240036,31370891)$ and Natural Science Foundation of Tianjin (13JCZDJC30000) 


\section{References}

[1] M. Esteller, N. Engl. J. Med. 358 (2008) 1148-1159.

[2] B.W. Futscher, M.M. Oshiro, R.J. Wozniak, Nat. Genet. 31 (2002) 175-179.

[3] W. Reik, A. Lewis, Nat. Rev. Genet. 6 (2005) 403-410.

[4] A. Eden, F. Gaudet, A. Waghmare, R. Jaenisch, Science 300, (2003) 455.

[5] A.P. Feinberg, B. Tycko, Nat. Rev. Cancer 4 (2004) 143-153.

[6] M.V. Brock, C.M. Hooker, E. Ota-Machida, Y. Han, M. Guo, S. Ames, S. Glockner, S. Piantadosi, E. Gabrielson, G. Pridham, N. Engl. J. Med. 358 (2008) 1118-1128.

[7] S.D. Gore, A. Jiemjit, L.B. Silverman, T. Aucott, S. Baylin, H. Carraway, T. Dauses, T.J. Fandy, J.E. Herman, Blood (ASH Ann. Meet. Abstr.) 108 (2006) 517.

[8] P.W. Laird, Nat. Rev. Cancer 3 (2003) 253-266.

[9] T. Mikeska, J.M. Craig, Genes 5 (2014) 821-864.

[10] G.J. Jenkins, G.L. Williams, J. Beynon, Z. Ye, J.N. Baxter, J.M. Parry, Br. J. Surg. 89 (2002) $8-20$.

[11] J.G. Herman, J.R. Graff, S. Myohanen, B.D. Nelkin, S.B. Baylin, PNAS 93 (1996) 9821-9826.

[12] K.C. Chan, P.B. Lai, T.S. Mok, H.L. Chan, C. Ding, S.W. Yeung, Y.M. Lo,. Clin. Chem. 54 (2008) 1528- 1536.

[13] T. von Kanel, D. Gerber, A. Schaller, A. Baumer, E. Wey, C.B. Jackson, F.M. Gisler, K. Heinimann, S. Gallati, Clin. Chem. 56 (2010) 1098-1106.

[14] E.Capel, J.F. Flejou, R.Hamelin, Oncogene 26 (2007) 7596-7600.

[15] K.P.M. Suijkerbuijk, X. Pan, E. Wall, P.J. Diest, M. Vooijs, Anal. Cell. Pathol. 33 (2010) $133-141$

[16] M.J. Fackler, M. McVeigh, J. Mehrotra, M.A. Blum, J. Lange, A. Lapides, Cancer Res. 64 (2004), 4442-4452.

[17] C.A. Eads, K.D. Danenberg, K. Kawakami, L.B. Saltz, C. Blake, D. Shibata, P.V. Danenberg, P.W. Laird, Nucleic Acids Res. 28 (2000) E32.

[18] J. Hu, C.Y. Zhang, Biosens. Bioelectron. 31 (2012) 451-457. 
[19] Q. Xue; Y. Lv, S.Xu, Y. Zhang, L. Wang, R. Li, Q. Yue, H. Li, X. Gu, S. Zhang, J. Liu, Biosens. Bioelectron. 66 (2015) 547-553.

[20] S.E. Kim, M. Chang,C. Yuan, Biosens. Bioelectron. 58 (2014) 333-337.

[21] X. Li, T. Song, X. Guo, Analyst 140 (2015) 6230-6233.

[22] S. Pan, J. Xu, Y. Shu, F. Wang, W. Xia, Q. Ding, T. Xu, C. Zhao, M. Zhang, P. Huang, S. Lu, Biosens. Bioelectron. 26 (2010) 850-853

[23] Y. Zhou, B. Li, M. Wang, Z. Yang, H. Yin, S. Ai, Anal. Chim. Acta 840 (2014) 28- 32.

[24] Y. Li, C. Huang, J. Zheng, H. Qi, Biosens. Bioelectron. 38 (2012) 407-410.

[25] Y. Geng, J. Wu, L. Shao, F. Yan, H.X. Ju, Biosens. Bioelectron. 61 (2014) 593- 597.

[26] J.D. Suter, D.J. Howard, H. Shi, C.W. Caldwell, X. Fan, Biosens. Bioelectron. 26 (2010) $1016-1020$.

[27] V.J. Bailey, H. Easwaran, Y. Zhang, E. Griffiths, S.A. Belinsky, J.G. Herman, S.B. Baylin, H.E. Carraway, T.H. Wang, Genome Res. 19 (2009) 1455-1461.

[28] H.Q. Zhang, Q. Zhao, X.F. Li, X.C. Le, Analyst 132 (2007) 724-737.

[29] H. Suzuki, M. Toyota, H. Caraway, E. Gabrielson, T. Ohmura, T. Fujikane, N. Nishikawa, Y. Sogabe, M. Nojima, T. Sonoda, M. Mori, K. Hirata, K. Imai, Y. Shinomura, S.B. Baylin, T. Tokino, Brit. J. Cancer 98 (2008) 1147-1156.

[30] J. Veeck, E. Noetzel, N. Bektas, E. Jost, A. Hartmann, R. Knuchel, E. Dahl, Mol. Cancer 7 (2008) 83.

[31] H. Wang, R. Fan, X.Q. Wang, D.P. Wu, G.W. Lin, Y. Xu, Li, W.Y. Ann. Hematol. 92 (2013) 199-209.

[32] J. Ying, G. Srivastava, W.S. Hsieh, Z. Gao, P. Murray, S.K. Liao, Clin. Cancer Res. 11 (2005) 6442-6449.

[33] P. Reddy, S. Ramlal, M.H. Sripathy, H.V. Batra, J. Immunol. Methods 408 (2014) 114-122. 


\section{Figure legends}

Fig. 1. Schematic presence of methylation-specific electrochemical biosensing strategy for DNA methylation detection.

Fig. 2. (A) EIS of bare GE (a), capture probe modified GE (b), capture probe/MCH modified GE (c), capture probe/MCH modified GE hybridizated with PCR product of bisulfite-converted genomic DNA (d), and (d) after reaction with ST-AP (e) in $0.5 \mathrm{mM} \mathrm{K} 3 \mathrm{Fe}(\mathrm{CN})_{6}{ }^{3-/ 4-}$ containing 0.4 $\mathrm{M} \mathrm{KCl}$ at scan rate of $100 \mathrm{mV} / \mathrm{s}$.

Fig. 3. Analysis of SFRP2 CpG methylation in MB231 breast cancer cell and normal breast tissue by (A) gel image of conventional MSP, and (B) methylation (a) and unmethylation (b)-specific electrochemical biosensor. NBT, normal breast tissue; M, PCR with methylated primers; U, with unmethylated primers.

Fig. 4. DPV curves of prepared electrochemical biosensors responding to PCR products without biotin labeling (a) and with different biotin labeling means by using biotin-labeled detection probe (b), and 1:2, 1:4, 1:9 of biotin-dUTP:dTTP (c-e) and biotinylated forward primer (f) incorporation for PCR.

Fig. 5. (A) Gel image of conventional MSP and (B) DPV curves of designed methylation-specific electrochemical biosensor responding to (a) $250 \mathrm{ng}$ of MB231 breast cancer cell genomic DNA, (b-e) $10 \%, 1 \%, 0.1 \%, 0.01 \%$ MB231 breast cancer cell genomic DNA spiked in $250 \mathrm{ng}$ of normal breast tissue genomic DNA, and (f) $250 \mathrm{ng}$ of normal breast tissue genomic DNA. Inset: plot of DPV peak current vs varying levels of SFRP2 methylation, the error bars represent the standard deviations calculated from three separate experiments.

Fig. 6. Analysis of SFRP2 CpG methylation status by (A) gel image of conventional MSP and (B) methylation-specific electrochemical biosensor in breast primary tumor tissues (a-c), MB231(d, e) and MCF-7 (f, g) breast cancer cell lines before $(\mathrm{d}, \mathrm{f})$ and after $(\mathrm{e}, \mathrm{g})$ demethylation treatment using Aza and TSA, respectively. $M$ and red curves, methylated; $U$ and black curves, unmethylated.

Table 1. Oligonucleotides used in the present study. 


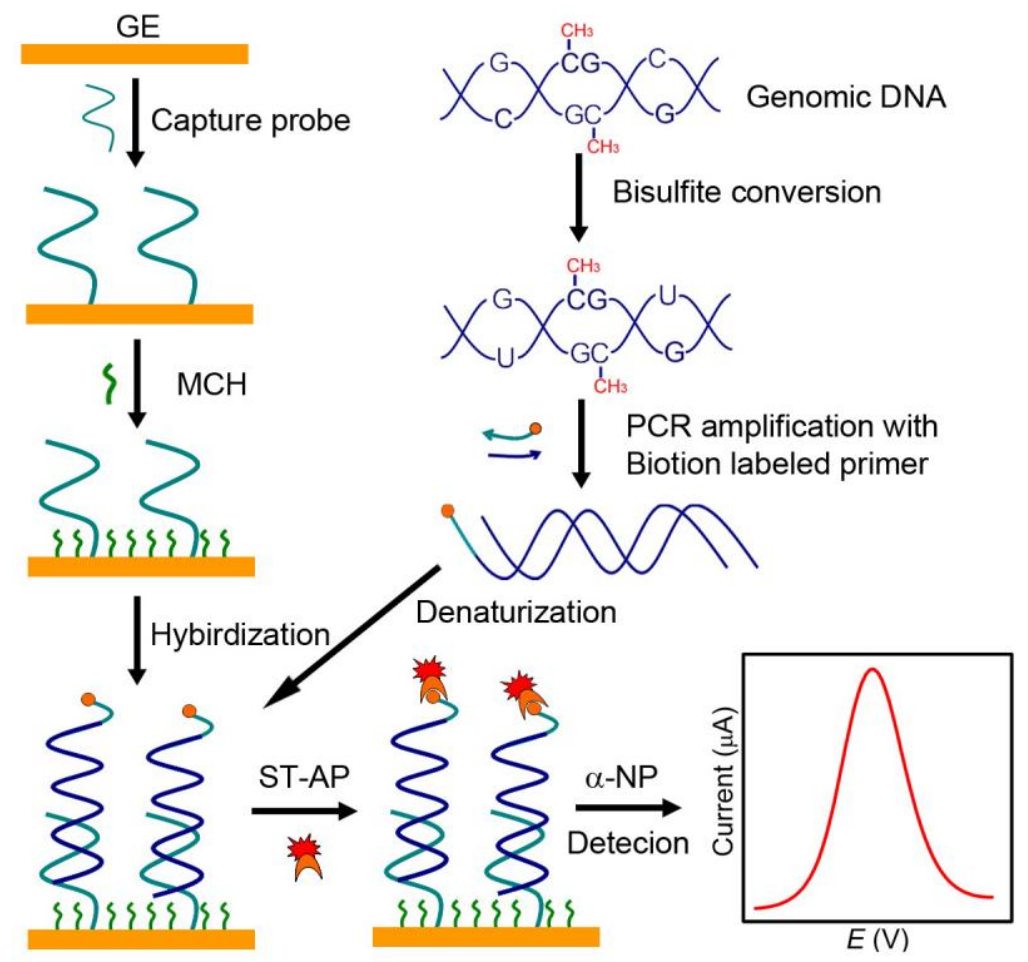




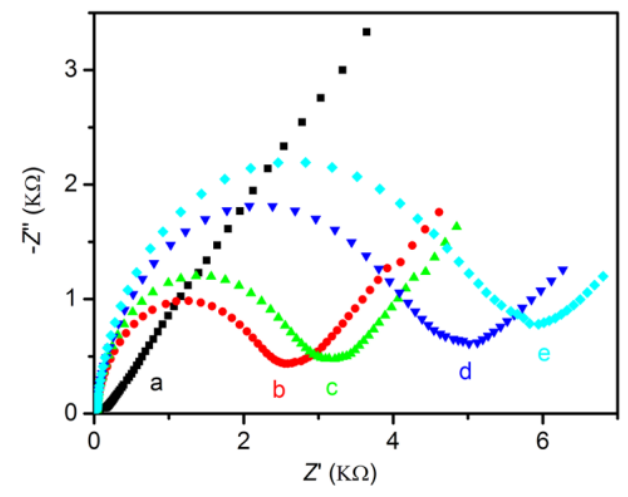




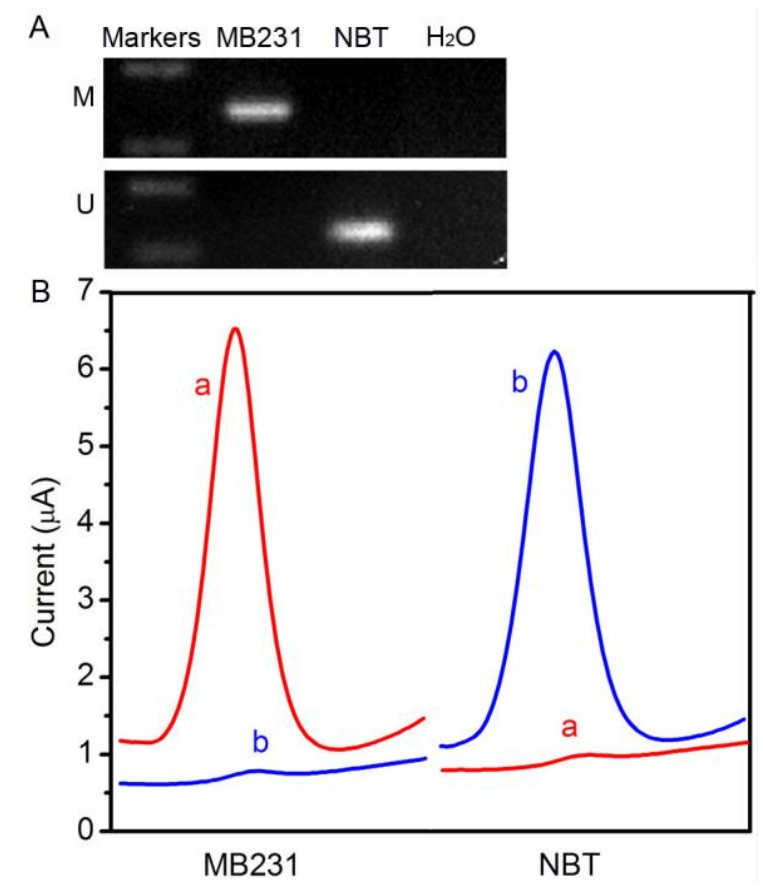




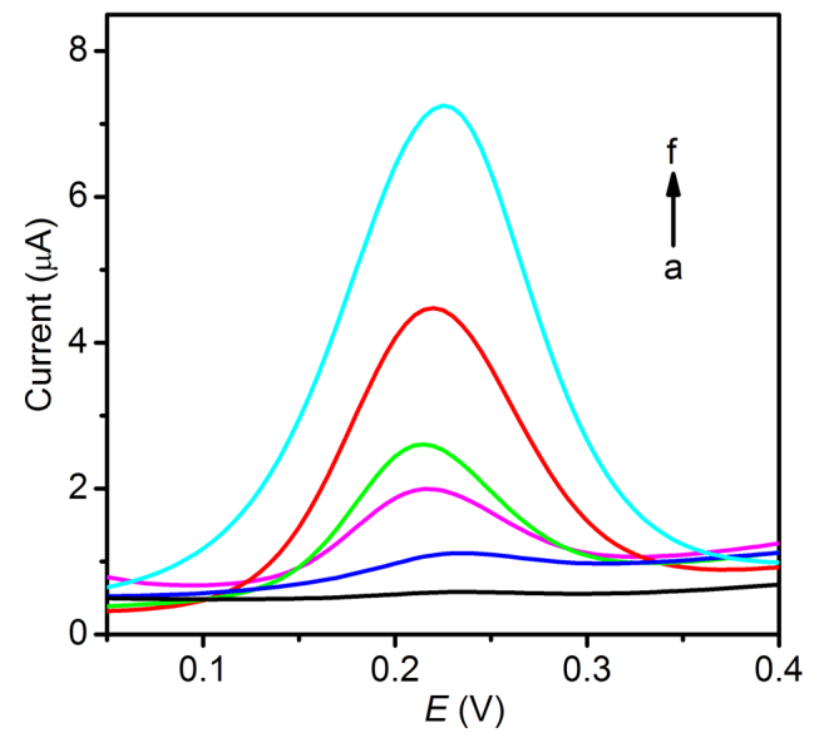




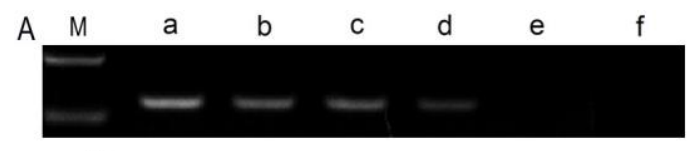

B

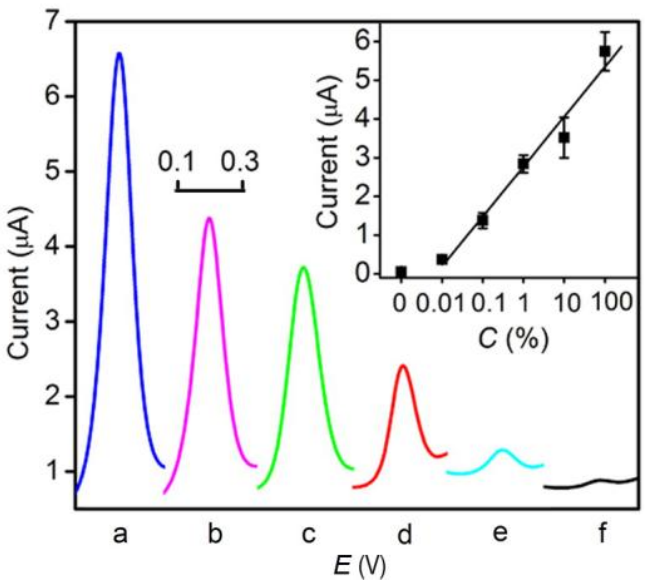




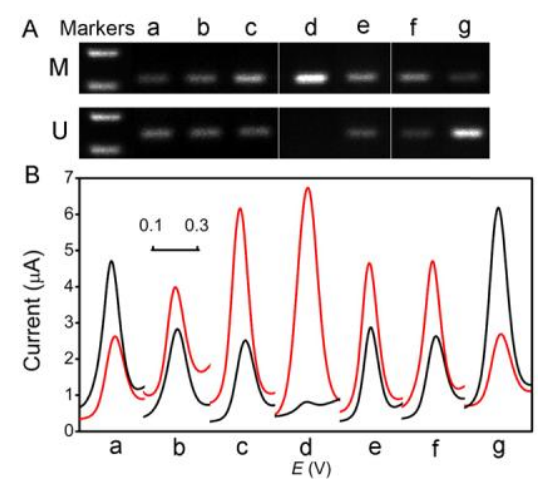




\begin{tabular}{ll}
\hline Oligonucleotide & Sequence(5'-3') \\
\hline Methylated forward primer & Biotin-GGA GTT TTT CGG AGT TGC GC \\
Methylated reverse primer & CTC TTC GCT AAA TAC GAC TCG \\
Unmethylated forward primer & Biotin-GTT GGA GTT TTT TGG AGT TGT GT \\
Unmethylated reverse primer & CTC TCT TCA CTAAAT ACA ACT CA \\
Methylated capture probe & HS- $\left(\mathrm{CH}_{2}\right)_{6}$-AAA AAA AAA CGA CTA AAA CGC \\
& GAAAA ACG \\
Unmethylated capture probe & HS- $\left(\mathrm{CH}_{2}\right)_{6}$-AAA AAA AAA CAA CTA AAA CAC \\
& AAAAAACA \\
\hline
\end{tabular}




\section{Graphical abstract}

Methylation-specific electrochemical biosensing strategy for highly sensitive and quantitative analysis of promoter methylation of tumor-suppressor gene in real sample

By Shenglin Liu, Xuejun Zhang, Kebin Zhao*

A handy and practical methylation-specific electrochemical biosensing strategy was developed by integrating bisulfite conversion and PCR amplification with high efficient electrochemical biosensor and successfully applied to quantitative detection of methylation level of target gene promotor and subtly monitoring methylation status changes in real sample.

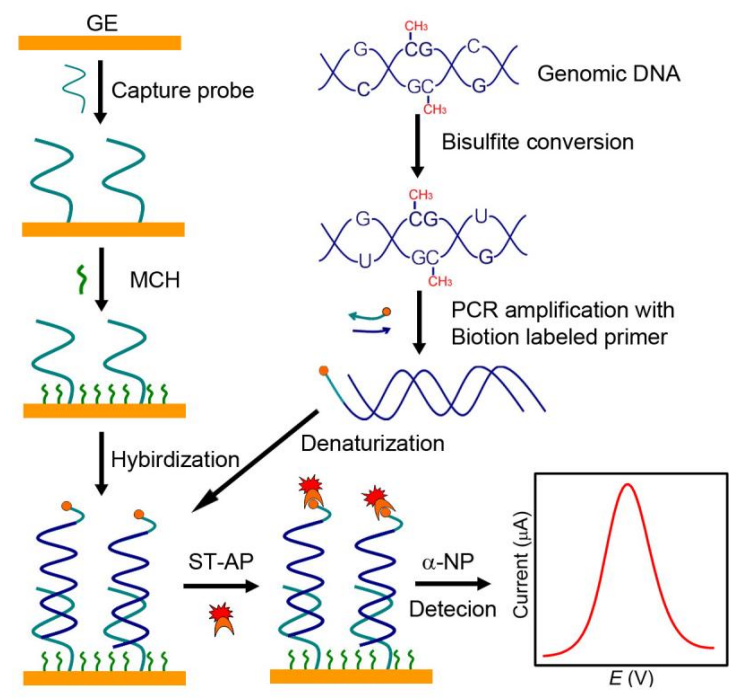

